\title{
Digital technologies in quality and efficiency management of transport service
}

\author{
Marina Vasilenko ${ }^{1,}$, Elena Kuzina ${ }^{2}$, Vadim Bespalov ${ }^{3},{\text { Nikita } \text { Drozdov }^{4}, \text { Julia } \text { Tagiltseva }}^{5}$, \\ Natalia Korenyakina ${ }^{6}$, Vladimir Prokopchuk ${ }^{2}$, and Pavel Nadolinsky ${ }^{2}$ \\ ${ }^{1}$ Rostov State Medical University, RostGMU of the Ministry of Health of Russia Nakhchivansky \\ lane, 29, 344000, Rostov-on-Don, Russia \\ ${ }^{2}$ Russian University of Transport. RUT - MIIT, Obraztsova, 9, building 9, 127994, Moscow, Russia \\ ${ }^{3}$ Don State University, Gagarin square, 1, 344003, Rostov-on-don, Russia \\ ${ }^{4}$ Technological institute (branch) of Don state technical university in Azov,Promyshlennaya st.,1, \\ 346780, Azov, Russia \\ ${ }^{5}$ Russian customs Academy Rostov branch, 20 Budennovsky Ave., 344002, Rostov-on-Don, Russia \\ ${ }^{6}$ Rostov State University of Railway Transport (RSUPS), pl. Rostov Rifle Regiment of the People's \\ Republic of Tatarstan Opolcheniya, 2, 344038, Rostov-on-Don, Russia
}

\begin{abstract}
The digital transformation of transport systems is one of the priority areas of the country's strategic development, and requires joint participation and interaction of the state, transport industry enterprises, innovative companies - developers of new technologies and equipment. Constant price pressures and growing customer demands for product and service quality complicate the challenges faced by rail organizations. All these organizations, and first of all JSC Russian Railways, within the framework of the ongoing structural reform, cannot increase the efficiency of their activities using the traditional set of technological, organizational and management solutions to reduce costs for all business processes and divisions of the company. The current state of the Russian economy already allows us to note positive shifts in the field of digitalization. The digitalization of transport as one of the social sectors, the use of modern technical means and programs, makes it possible to increase the efficiency of the transport complex, to ensure high quality services. The authors considered digital technologies in JSC "Russian Railways" used to increase flexibility, efficiency and quality of service provision. The key electronic platforms used by Russian Railways in its work are presented. Disclosed telematic systems used in railway transport to improve safety. Methods are proposed for improving the quality of passenger service at railway stations in the Russian Federation.
\end{abstract}

\section{Introduction}

Digitalization acts as one of the main trends in the development of the economy and society as a whole and is the preferred direction of the state's economic strategy [1].

\footnotetext{
*Correspondent author: margo2026@yandex.ru
} 
An important task of our time is the development of transport technologies. Digital transport development is an integral component of a successful transition to the development of transport systems.

High competition in the freight transportation market requires an increase in the efficiency of railways and their attractiveness to customers. Therefore, in the railway community, the need for digitalization of the transportation process is long overdue [2].

Digitalization is a process that should make the economy of Russian Railways competitive, efficient, and the main production task - the transportation of passengers and cargo - in line with modern technological standards. The digitalization of railway transport will give a significant impetus to the development of the economy.

\section{Materials}

Currently, digitalization is considered as the main way to improve the efficiency of the national economy and its transport industry [3]. Digital technologies are gradually penetrating all areas of Russian business. The introduction of advanced tools in the transport industry is especially productive. It is the efficiency of using the latest technological advances that determines the competitiveness of transport companies, and in this context, the study of the impact of digital technologies on production processes is of greatest practical interest.

Digitalization as an economic phenomenon in their works was considered by scientists: T.V. Avdienko, A.N. Dmitrievsky, T.N. Yudina, N.P. Tereshina, V.P. Bychkova, V.I. Belova, A. L. Kuznetsov, V. A. Plotnikov, K.V. Ilyina, L.A. Kargin, S.L. Lebedev, V.A. Shlein, E.A. Ivanova, A.I. Zaboeva, N.A. Zhuravleva, E.K. Korovyakovsky, V.P. Kupriyanovsky, O. N. Larin, A. Yu. Panychev, M.V. Sigova, M. Yu. Sokolov, G.V. Sukonnikov, B.A. Levin, E.N. Rosenberg, V.I. Lyashenko, Yu.S. Smagin, D.V. Efanov, J. E. Grunig, G. Shi, C. Liu; S. Zhao, I. Salaberria, A. Perallos, L. Azpilicueta, F. Falcone, R. Carballedo, I. Angulo, P. Elejoste, A. Bahillo, A.J. Ritchie, J.J. Astrain, J. Villadangos.

In 2017, by order of the Government of the Russian Federation dated July 28, No. 1632$r$, the program "Strategy for the development of the information society in the Russian Federation for 2017-2030 was approved (approved by the Decree of the President of the Russian Federation No. 203 dated May 9, 2017), the Program“ Digital economy of the Russian Federation "(approved by the order of the Government of the Russian Federation dated July 28, 2017 No. 1632-r) [4], after which measures were taken to implement it. Thus, digitalization is currently in the spotlight of the public and researchers.

The transport industry is one of the areas of economic activity that is most affected by digitalization processes. This influence can be divided into obvious, superficial changes in this area and those that occur in the transport infrastructure itself [5].

The main goal of the Government of the Russian Federation is to form a single digital transport space in Russia, to make passenger and freight transportation safer, more convenient, accessible for people and business, to reduce costs, and to expand export and transit opportunities. To solve these problems, a departmental project "Digital Transport and Logistics" is provided, which is being developed as part of the state program for the development of transport.

\section{Results}

The introduction of elements of digital technologies stimulates transport companies to significantly intensify their competitive potential, to conduct constant research of the market environment to determine potential "growth reserves". 
Increasing the flexibility and quality of services provided by Russian Railways using the integration of information resources and systems are shown in Figure 1.

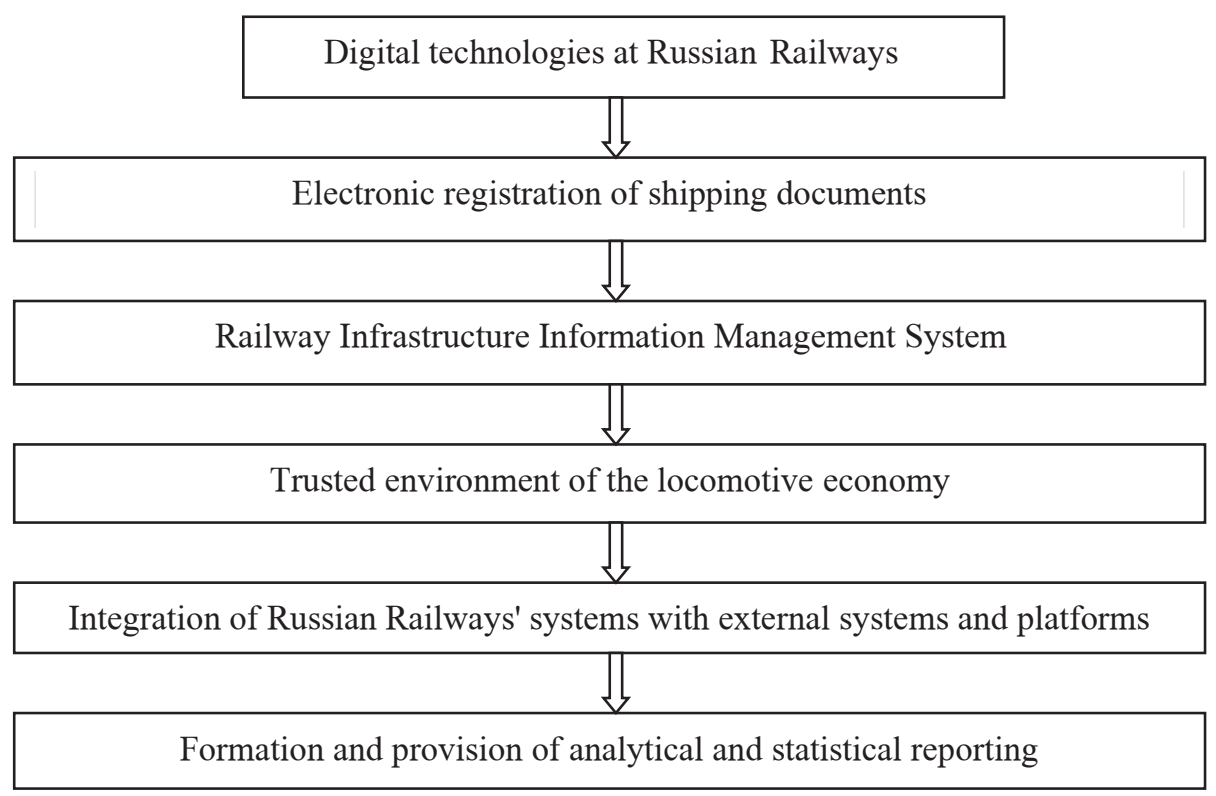

Fig. 1. Digital technologies at Russian Railways

The development of digital systems is intended, first of all, to improve the quality of life, make transport more convenient for people and business development, and innovative developments in modeling transport systems and regulating traffic flows should provide end users with greater information content and safety, as well as qualitatively increase the level of interaction between participants [6].

Transport needs the most modern digital technologies in order to remain competitive in the world market, to meet the need for the transportation of increasing volumes of passengers and goods, to ensure the availability and quality of services [7].

Digital technologies affect business development, and also act as the main condition for survival in the fierce competition in the cargo transportation market. Thanks to them, it is possible to offer a more competitive product, not only making it more convenient for the consumer, but also reducing its cost [8].

The digitalization strategy of Russian Railways is based on the creation, implementation of key electronic platforms, and integration with the global transport system (Figure 2.). 


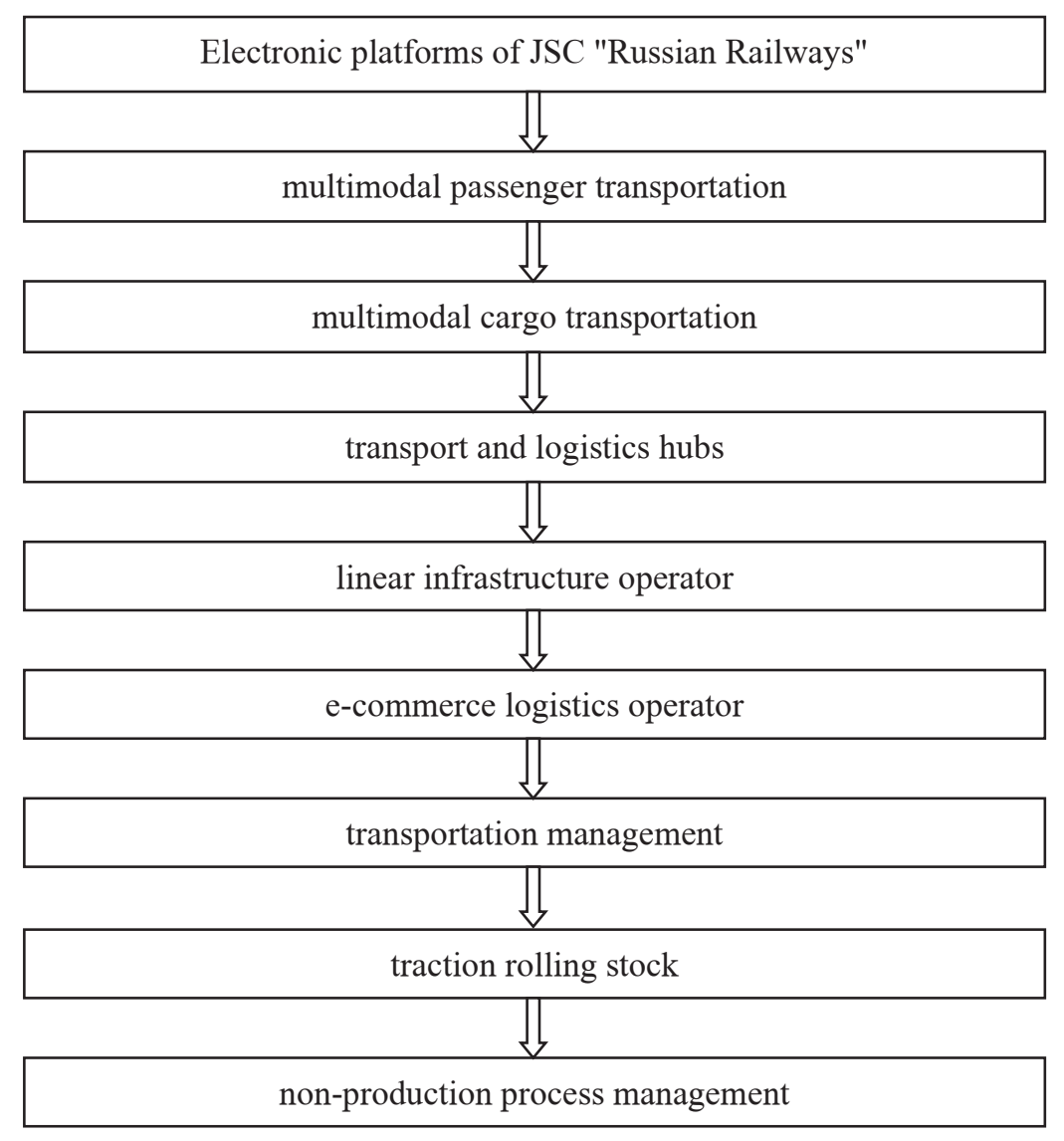

Fig. 2. Key electronic platforms of Russian Railways

According to Oleg Belozyorov, with the introduction of electronic platforms, the effect for Russian Railways will be more than 150 billion rubles. At the same time, the indirect effect that the partners of the holding will receive will amount to about 500 billion rubles.

\section{Discussion}

The objective need of the transport industry for new innovative developments is very high. The economic effect that the introduction of digital technologies brings in the transport sector is obvious and tangible. Savings are realized by reducing off-target costs, increasing control and manageability of the system. At the moment, there is experience in the implementation of digital technologies in transport: the introduction of remote control, comprehensive automation, the introduction of integrated technologies, as well as intelligent control systems. It is worth noting that the labor intensity and high investments that the introduction of new solutions requires are justified. After all, the risks associated with the rejection of this activity are incomparably higher. Among them are lagging behind the market, loss in quality, increased costs, customer churn [9].

Digital management in the implementation of cargo transportation includes electronic document management (payment of duties and registration of customs documents), allows you to choose the optimal methods of delivery of goods, plan routes depending on road load, track the location and condition of goods and, of course, optimize the work of personnel [10]. 
Digital technologies in the implementation of passenger transportation allow introducing a single ticket and expanding loyalty programs for passengers.

The future belongs to digital technologies, therefore leading Russian transport companies are investing in their development. The main guarantor of investment protection in digital technologies is the state.

The value of a transport service is primarily associated with its cost, which is provided in a new technological order by the speed of transportation (including the time of ordering, registration, direct transportation, payments for it or the time of the operational and financial cycle) [11]. In a transport service, it is not only the time of travel by transport of one type or another or their combination that becomes important, but also the time, and therefore the value of owning this service (door to door).

Telematics systems are used to improve safety in rail transport. With the help of a data generator and a radio communication system installed on each carriage, safety information is sent to operations centers [12]. With the help of telematic services, data on the movement and operating mode of transport are transmitted. Electronic systems collect information from macrographs, GPS trackers, as well as sensors at various machine nodes [13]. Telematics allows remote monitoring of air temperature and humidity, vibration level and transportation conditions in a refrigerator container. As a result, the user has the opportunity to receive and analyze information about the functioning of the transport system in real time.

In April 2020, a new website was launched for railway passengers, which makes the process of purchasing tickets more convenient and allows increasing customer awareness. And this is an important component of the development of the Russian Railways digital platform, the key element of which is multimodality: more additional services both on board the train and outside the infrastructure. One example is the transportation of passengers by train and bus, the flights of which are docked at the time of departure and arrival. And here, just as in cargo transportation, in conditions when the passenger traffic for obvious reasons decreases, digital services become a competitive advantage.

The implemented project "Innovative Mobility" sets the main goal of launching and developing a full-fledged platform for innovative mobility in the country, providing planning, booking and payment services for passenger transportation by various modes of transport, as well as additional related services through a single interface.

The "Hitcher" digital portal and the Russian Railways for Passengers mobile application already provide users of suburban and long-distance rail transport services with a variety of services, from purchasing electronic tickets to navigating through train stations and providing multimedia content on board trains. The block - chain digital platform "Cargo Transportation" built on the block - chain technology should ensure the digitalization of services for ordering and registration and transportation of goods. Working with the platform will allow shippers to reduce the process of cargo clearance and other related services from three weeks to 7 minutes. During this year, through the platform, it will be possible to order delivery not only by rail, but also by road, as well as arrange warehousing and insurance services and financial services. The design of all services will be based on smart contract technology.

The development of electronic systems and services based on the use of digital technologies at railway stations contributes to an increase in the efficiency and quality of transport services for passengers [14]. At present, video surveillance and digital image recognition systems are being improved to ensure safety, including those based on the MATLAB software product [15], which make it possible to determine in real time the number of passengers at the station, the density and speed of passenger traffic, and ensure the safe movement of passengers at railway stations, in transitions and on platforms. The technical capabilities of high-quality provision of mobile communication and Internet services at transport facilities and on the way are being improved [16], which contributes to an increase 
in the level of awareness and satisfaction of passengers with additional services in transport. The quality of integrated transport services has a predominant effect on demand, therefore the best way to retain a consumer is to satisfy or exceed his needs [17]. The electronic environment is becoming the main assistant in the implementation of this task.

General proposals for expanding services and developing the digital environment of railway stations in the Russian Federation are presented in Figure 3.

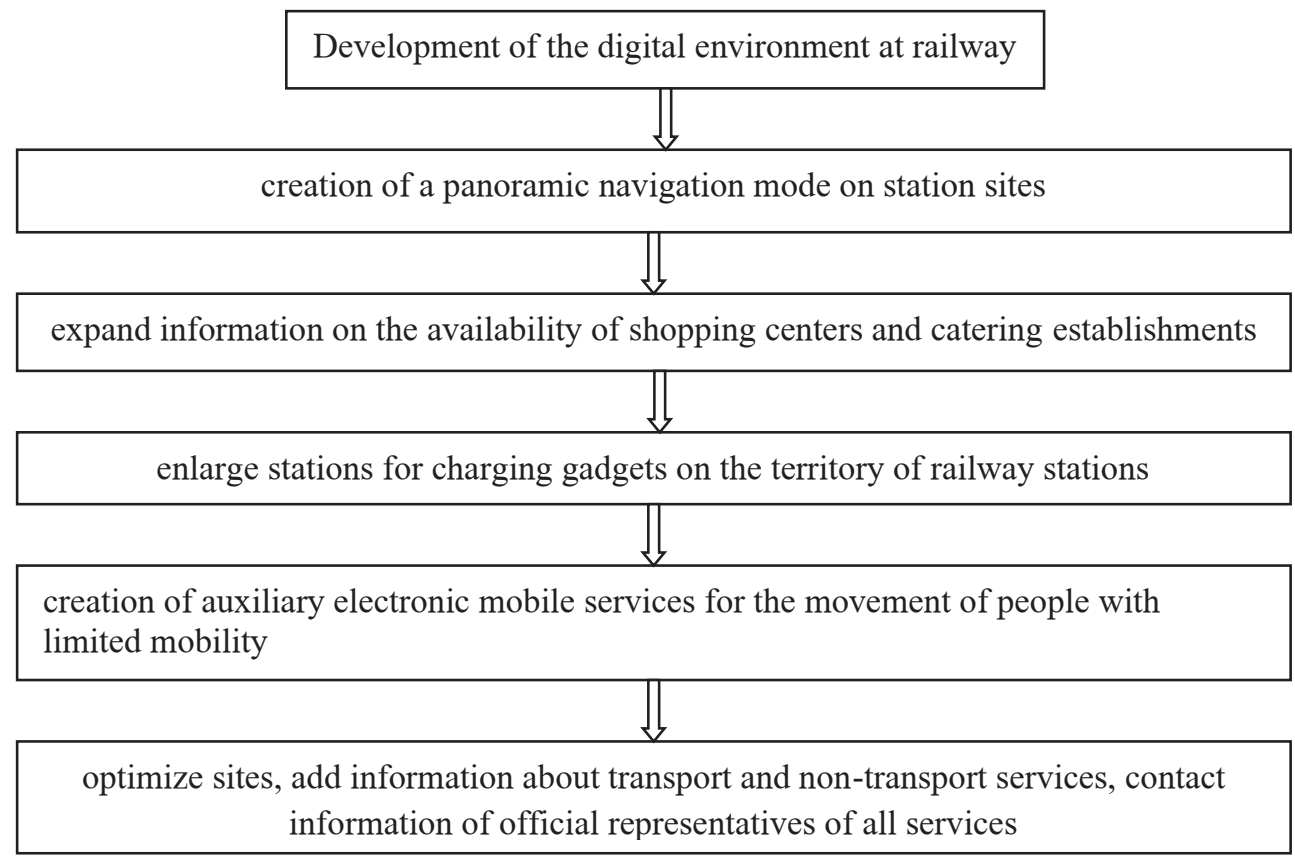

Fig. 3. General proposals for expanding services and developing the digital environment of railway stations in the Russian Federation

To improve the quality of passenger service at railway stations in the Russian Federation and increase their financial and economic results, it is necessary to install electronic information and navigation terminals (kiosks), to continue to develop the convenience and information content of the station sites [18].

Electronic information and navigation terminal (kiosk) is an automated software and hardware complex designed to provide reference information and navigation around the station, it is proposed to install them at the entrances to the station buildings. These means of informing are convenient in that the client receives all the information of interest in selfservice mode. Such stands are more effective than the usual signs, they will make it easy to navigate anywhere in the station complex. The interactive navigation panel includes a touchscreen terminal and special software. Through the electronic kiosk you should:

- provide complete information about the services at the station; cafes, shops, hotels located in the building; services of the station partners;

- inform about the schedule of departure and arrival of long-distance trains, suburban electric trains from all stations of the city;

- inform about other types of transport (buses, trams, trolleybuses, bicycle stations) and official taxis;

- broadcast the latest news.

The effects from the implementation of proposals for the development of the electronic environment of stations and the creation of new services for passengers based on the use of digital technologies can be divided into: the formation of a positive image of the territories 
served by the transport company; economic effects and improving the image of the Russian Railways holding, economic effects for business partners of the Holding's railway station complex, as well as qualitative effects for passengers as a result of improving a number of indicators of the quality of transport services.

The creation of a positive corporate image of an innovative, modern and customeroriented company is an important tool for strengthening market positions, attracting passengers and generating future financial flows of Russian Railways [19].

The efficiency of the transportation service is ensured by the proper cargo and passenger traffic, the speed of movement and the density of the transport network. The creation of a network of values of the transport service is due to the transformation of transport and logistics systems into integrated logistics support for production and consumption. This means that the strategy of the new business model should be based on multimodal transport, long-term service relationships, where there is a distributed end-to-end trust environment (distributed ledger technology) and a blockchain tool that records every transaction in real time. In assessing the effectiveness of the digitalization of transport systems, the "unit of value" indicator can be used. It can be calculated as "the weighted average sum of three subindices: the development of transport infrastructure and services, the cost of introducing and maintaining digital assets, freight and passenger traffic.

A transport organization can form a new product of intermodal transportation of goods in a container based on a distributed ledger using blockchain technology. This is a clear value proposition. And if the infrastructure of the project is built on a technology that ensures a transportation speed of more than $500 \mathrm{~km} / \mathrm{h}$, then the organization - the initiator of the project will offer an absolute network of values that changes the essence of the transport service. The new business model of such a project will create an effect in increasing the throughput and carrying capacity (speed) of the transport system and the real growth of the marginal profitability of shippers.

In Russia, the digital solutions market, unfortunately, does not recoup the costs of developing new technologies, since it is too small. RF is a segment of the global digitalization market [20]. Digitalization programs should be aimed at solving specific problems, taking into account the needs of the client or the value to the client. Digitalization makes sense only when it provides profit monetization. It is impossible to increase the efficiency of transport systems without the introduction of digital technologies, just as it is impossible to implement transport digitalization projects within the framework of old business models. The creation of new business models for the activities of organizations in the transport market is becoming the most important factor in the industry's entry into the format of a new technological order.

The updated transport system, which uses information technology, ensures a clear, wellcoordinated work of all links in the transportation of passengers, cargo, maximum comfort, quality and speed of transportation [21-22].

\section{Conclusions}

Digitalization is a key element in the qualitative improvement of railway transport in all its aspects - reliability, accuracy of adherence to traffic schedules, user interface, etc. Increase in labor productivity, throughput, optimization of infrastructure and rolling stock maintenance, reduction of fuel consumption - all these are expected and very significant effects of digitalization. This, in turn, will increase the volume of cargo and passenger traffic.

It is worth noting that in 2020 there is an increase in the profitability of JSC "Russian Railways" due to the provision of high-quality digital services, improvement of the quality of transport services, which, in turn, was achieved by reducing the lead time, which ultimately led to an increase in the number of customers. 


\section{References}

1. V. A. Plotnikov, Digitalization of production: theoretical essence and development prospects in the Russian economy. Bulletin of the St. Petersburg State University of Economics, 4(112), 16-25 (2018)

2. A. M. Romanchikov, V. A. Gross, D. V. Efanov, A. Yu. Vasiliev, Digitalization of railway transport in Russia. Transport of the Russian Federation. A journal about science, practice, economics, 6(79) https://cyberleninka.ru/article/n/tsifrovizatsiya-zheleznodorozhnogo-transporta-v-rossii (Last accessed 16.01.2021)

3. N. A. Zhuravleva, Problems of introducing digital technologies in transport. Transport of the Russian Federation. A journal about science, practice, economics, 3(82) (2019) https://cyberleninka.ru/article/n/problemy-vnedreniya-tsifrovyh-tehnologiy-natransporte (Last accessed 01/13/2021).

4. Program "Digital Economy of the Russian Federation" (approved by the order of the Government of the Russian Federation dated July 28, 1632-r (2017)

5. N. A. Mashkina, The influence of the digital economy on the development of the transport industry in the world. TsITISE, 1(20), 290-299 (2020)

6. N. Yu. Lakhmetkina, I. V.Shchelkunova, D. A. Rogova, Development of transport systems in the digital agenda. Intellect. Innovation. Investments, 4, 114-120 (2019)

7. A. A. Petrov, Digital Economy: Russia's Challenge in Global Markets. Trade Policy, 1(13), 44-75 (2018)

8. E. A. Saksonov, Y. L. Leokhin, V. N. Azarov, Organization of Information Security in Industrial Internet of Things Systems. Proceedings of the 2019 IEEE International Conference Quality Management, Transport and Information Security, Information Technologies IT and QM and IS (2019)

9. A. L. Kuznetsov, A. V. Kirichenko, V. N. Shcherbakova-Slyusarenko Directions of digitalization of the transport industry. Bulletin of the State University of Marine and River Fleet named after Admiral S. O. Makarov, 6, 1179-1190 (2018)DOI: 10.21821 / 2309-5180- 2018-10-6-1179-1190.

10. D. B. Efimenko, E. S. Barabanova, A. I. Tkacheva, Application of digital technologies in the development of transport support for foreign economic activity. Transport Bulletin, 10, 14-17 (2019)

11. N. A. Nemanova, Development of a competitive commercial proposal for the transportation of goods in containers. Economy of railways, 1, 42-53 (2020)

12. I. L. Yustratova, M. V. Kuznetsova, The use of innovative technologies in the activities of freight motor transport companies. National and international financial and economic problems of motor transport, 182-187 (2019)

13. E. A. Ivanova, V. A. Shlein, Image and economic aspects of the implementation of digital services for passengers at railway stations. Transport business of Russia, 4, $22-$ 25 (2020)

14. L. A. Kargina, S. L. Lebedeva, Use of digital technologies in the transport sector. TRANSPORT BUSINESS IN RUSSIA, 4, 75-78 (2018)

15. G .Shi, C .Liu, S. Zhao, Research on Passenger Recognition System Based on Video Image Processing in Railway Passenger Station. Proceedings of the first international conference on information sciences, machinery, materials and energy (ICISMME 2015) Series: Advances in Intelligent Systems Research, 126, 1145-1148 (2015) 
16. I. Salaberria, A. Perallos, L. Azpilicueta, F. Falcone, R. Carballedo, I. Angulo, P. Elejoste, A. Bahillo, J. J. Astrain, J. Villadangos, Ubiquitous Connected Train Based on Train-to-Ground and Intra-Wagon Communications Capable of Providing on Trip Customized Digital Services for Passengers. Sensors, 14, 8003-8025 (2014)

17. Strategy for the development of the information society in the Russian Federation for 2017-2030 (approved by the Decree of the President of the Russian Federation dated May 9, 2017 No. 203).

18. N. A. Zhuravleva, Methodology for studying digital transformation in the context of destabilization of business models of transport organizations. Methodology for the development of the economy, industry and services in the context of digitalization, 1047 (2018)

19. N. A. Drozdov, M. A. Vasilenko, Ya. A. Tagiltseva, E. L. Kuzina, S. V. Semibratova, V. S. Abramov, Social And Ecological Safety, Production Processes, Economic Efficiency In Transport Enterprises. European Proceedings of Social and Behavioral Sciences EpSBS, 1661-1670 (2020) Doi: 10.15405 / epsbs.2020.10.05.219 https://doi.org/10.15405/epsbs.2020.10.05.219

20. M. A. Vasilenko, E. L. Kuzina, N. A. Drozdov, J. A. Tagiltseva, Evaluation of the effectiveness of environmental management decisions. 2018 IEEE Conference of Russian Young Researchers in Electrical and Electronic Engineering (EIConRus) 12811285 (2018) DOI: 10.1109 / EIConRus.2018.8317330

21. M. A. Vasilenko, Ya. A. Tagiltseva, N. A. Drozdov, E. L. Kuzina, The main directions of developing jrganizational measures at the railway rnterprises in the corporate social responsibility aspect. 2018 IEEE International Conference "Quality Management, Transport and Information Security, Information Technologies" (IT \& QM \& IS). St. Petersburg, Russia, 163-168 (2018) DOI: 10.1109 / ITMQIS.2018.8524961 http://www.ieee.spb.ru (Last accessed 16.01.2021)

22. M. A. Vasilenko, Yu. A. Tagiltseva, S. Sh. Magomedov, V. A. Galkin, Actual approaches to assessing the management efficiency of the socio-ecological-economic system. Main trends in the development of economics and management in modern Russia, 84-88 (2019) 